International Journal of Engineering \& Technology, $7(2.19)(2018) 101-103$
International Journal of Engineering \& Technology
WPC
Website www.sciencepubco.com/index.php/IJET
Research paper

\title{
E-Application and Dss for Farmers to Sell Food Crops Through E-Auction
}

\author{
Dharmateja $\mathbf{M}^{1 *}$, Sriraman Kothuri ${ }^{2,}$ Kuna.Venkateswararao ${ }^{3}$ \\ 123 assistant Professor \\ Department Of Computer Science And Engineering, School Of Computing, \\ Vel Tech Rangarajan Dr. Sagunthala R\&D Institute Of Science And Technology, \\ Avadi, Chennai-600 062, Tamil Nadu, India. \\ *Dharmateja@Gmail.Com, Sriramankothuri@Veltech.Edu.In, Kvrvenkateshkvr@Gmail.Com
}

\begin{abstract}
Farmers have been facing issues while selling their food crops in market due to intermediate persons, who actually got profit by setting low price while buying from farmers and later sell the same at higher price to the customers. Through e-application is developed for farmers to set their own price to their products and allows buyers for e-auction. Farmers can set the initial bid amount based on quality, life time and current market price of the products before going for e-auction. The buyers can find nearest sellers through GPS navigation system. Choices locked once validity of bidding over and corresponding buyer, seller get notified through SMS. The interface also act as Decision Support System(DSS) for farmers to post their queries for getting advice's from agriculture specialists.
\end{abstract}

Keywords: GPS, E-AUCTION, DSS, SMS

\section{Introduction}

\subsection{Present Market System}

Most of the food crops like tomato's, carrot's, potato's, onion's...etc are carried into the market by farmers to sell in a particular day where intermediate persons are allowed for auction. Farmer will sold the products to the person who bid's more in auction. But during these days the intermediate personal are farming a committee and held meeting them self before auction starts and sets the maximum allowed price for all type of vegetable based on current market price and their profit. They also have rules like no individual personal should not buy the products more than the setting price else their membership will be canceled. After purchasing at lower price from farmers, they intentionally create a

demand in the market in next few days by storing goods in their storage facility and sell same at higher price to the end-users. This is the actual main hidden reason why farmers are forcefully sell their commodities at cheaper cost and why end-users are forcefully buying at higher cost in market at later time. In this existing system both farmers and end-users are lured due to the middleman's technique. The government also failed to set the far price to the food crops in agri-market. Farmers have been moving from villages to cities for the work by thinking agriculture is no more profitable zone. The unpredictable weather, duplicate seeds and pesticides in the market also changes their mindset to choose alternative profitable fields.

\subsection{Objectives}

-Agriculture is one of the main sectors where development is required in this digital era.

-The main objectives of the proposed web based online auction of food crops are exact crop cost.

-To allow farmers in freedom to set the price

-To eliminate the involvement of intermediate persons in market

-To elimination of demanding situation for Buyers (hotels, individuals, wedding hall function members..etc) by booking the needed food crops in advance

-The Rating provided by the buyers based on receiving quality of the products can be used to choose loyalty farmers and vice versa

-To make agriculture as a profitable zone.

-To eliminate unnecessary storing of food crops by contacting the buyers in advance and choose the plans accordingly.

-Use of GPS technology to show the nearest buyers to sellers and vice versa.

\subsection{Need for the Study}

- Minimum crop wastage

- Consumer satisfaction 
- Transparent bidding

- Better quality products

- $\quad$ Reduced transportation cost

\subsection{Expected Outcomes}

The main objective behind this proposal is to make agriculture field as profitable by creating a suitable decision support application for farmers to not only sell their products through e-auction but also get advises to their problems. Farmers need to login in order to sell their food crops, on successful login they need to specify the nearest market where they want to sell along with specifying date and images of the products, quantity and initial bid amount as minimum amount. Buyers also need to login in order to buy from nearest sellers by giving market details where they want to buy. On successful login they can search products and choose one from the list of available sellers, in order to participate in bidding they need to specify their bid amount. people from hotels, wedding halls can book required quantity of their needs along with transportation cost from sellers by giving equivalent market price without participate in bidding to avoid unnecessary worrying at later time during functions or marriages. During registration both seller and buyer need to give account details in case of online payment. Rating points given to both parties based on their satisfaction levels with product.

After bidding over later help these to choose only loyalty sellers or buyers. The buyer or sellers are the solely responsible for goods delivery once they agreed.

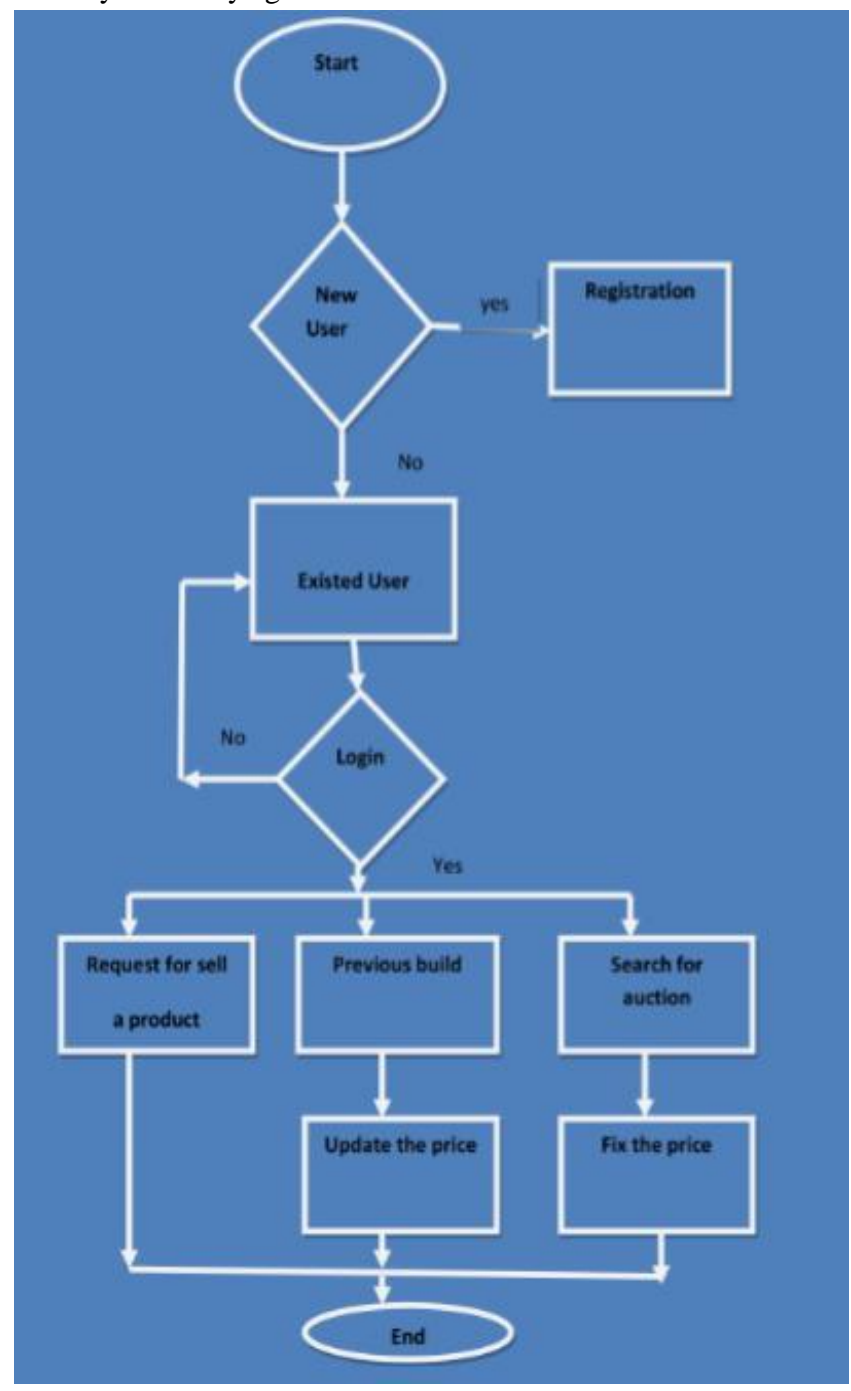

Fig 1 E-auction process
Both parties can go either cash on delivery or online payment after commit. This application also acts as recommendation system by analyzing the disease uploaded by farmers and recommends remedies. Hotels, canteens, housing societies can buy bulk low price high quality vegetables in advance by directly contacting the seller without bidding.

\section{Related Work}

Dijkstra's algorithm is used to find the nearest buyers to the sellers and vice versa. It is used for finding the shortest path between nodes in graph. It uses greedy technique inherently. It selects min distance at every step from available choices continues the same step. Once the destination reached it stops and returns the path.

Android studio is an Integrated Development Environment (IDE) for android application. The user Interface (UI) comes with basic layout. It also comes with installation of android SDK which provides basic platform and Android Virtual Device, where we can test the apps. Java development Kit (JDK) is needed for android studio to interpret and compile the code. Extensible Markup Language (XML) is used create layout buttons, fonts, text box etc. for app.

Global Positioning System (GPS) technology has different uses. We can use GPS technology to track goods, and given frequent updates about the location of the products to the buyer.

\section{Methodology}

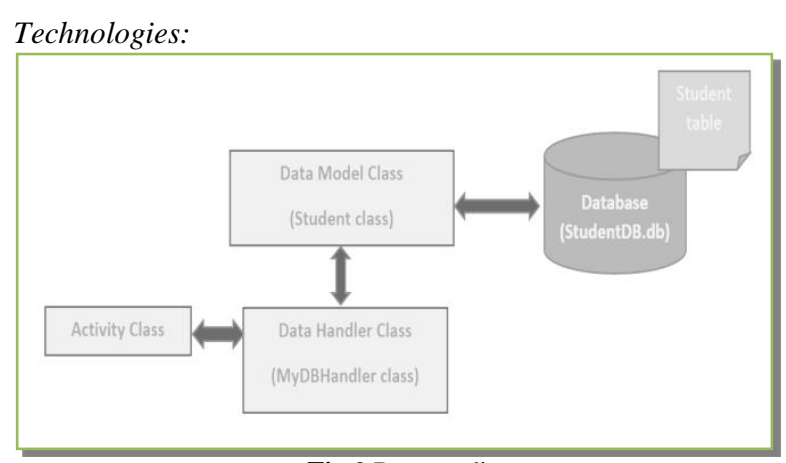

Fig.2 Process diagram

SQLite: SQLite is an open source $\mathrm{DB}$, mainly used to stores data to a text file on a user mobile device. By default Android has inbuilt SQLite DB. SQLite supports all the relational database features like insert/delete/alter on a structured data. No need to establish a connection to access database like JDBC, ODBC drivers.

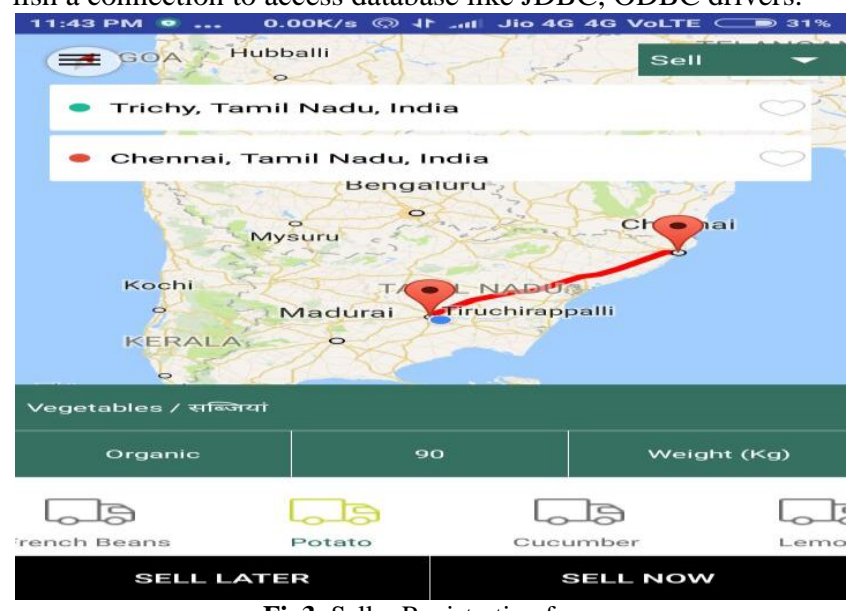

Fig3: Seller Registration form

The application will consist of an activity and a database handler class (MyDBHandler class). SQLiteOpenHelper has a subclass that will handle database handlers and act as abstract layer be- 
tween SQLite DB and activity class .In order to pass the data between activity class and the handler a third class (seller class) need to be implemented.

\section{Results}

To sell: After choosing option 'sell' from drop-down, a prompt(FIG-1) open by asking seller to enter source(place where user have vegetables) and destination(place where user want to sell) details. After entering the source and destination a path with red color will show on the map to show the distance between them. In below seller need to select the organic or hybrid type and in the next drop-down will show vegetables/rice/wheat. Based on seller option it will ask for weight of the products in $\mathrm{kg}$ 's/ton's/bag's correspondingly. Then in the down it will show a transported vehicle with list of vegetables.

The prompt also comes with options like 'sell now' or 'sell later'. If seller wants to sell the commodities based on market price or if present market is down for products then he can choose sell later option, where he needs to specify a date on which he wants to sell in next prompt. Otherwise he can choose 'sell now' option.

To Buy: If any buyer wants to buy or to participate in bidding in first time then he need to enter the basic

Details in the prompt (Fig-3) contains delivery destination (used to calculate transportation cost while bidding), preferred market (if he want to buy from a particular location), the products are categorized as vegetables or rice or wheat..etc. He needs to enter item that he wants to buy or bid by specifying quantity in kg's/ton's/bag's in the next fields, SMS will be sent to buyers during bid or if any product is confirmed those details sent to the mobile no he specified in 'mno-feild' before submitting form.

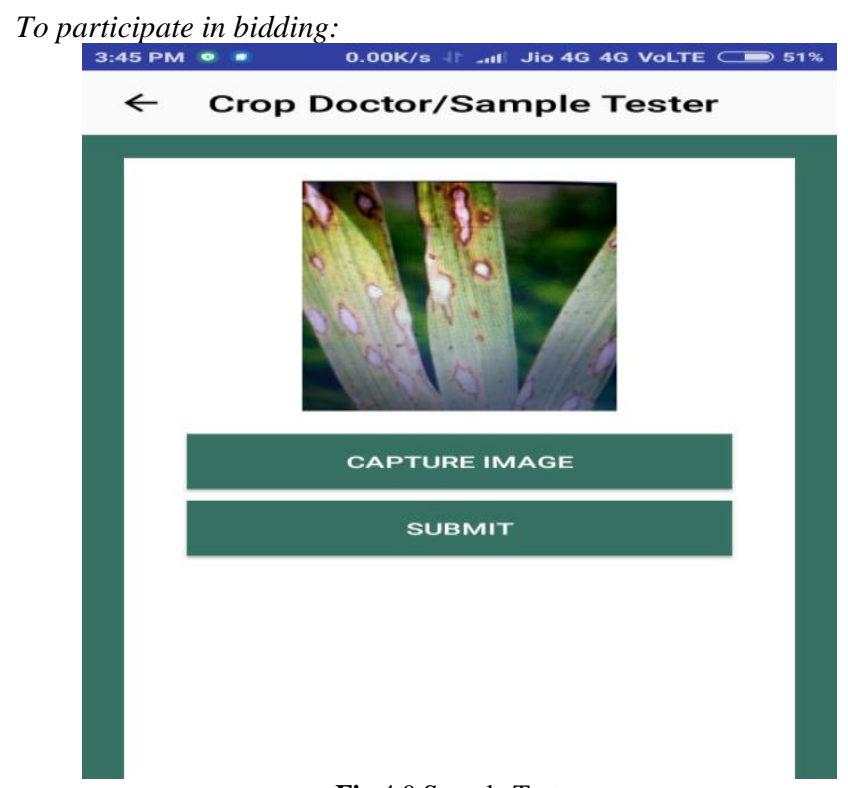

Fig 4.0 Sample Tester

The list of available items on that particular date in nearest to his location is shown. The prompt comes with by showing last bid value, images of the product, current market price including with transportation cost will be shown along with an options like 'buy now' or 'buy later' .if he click on buy now option then in the next field he needs to enter the amount more than the current bid value and an SMS will be sent to the previous bidder about new bid value.

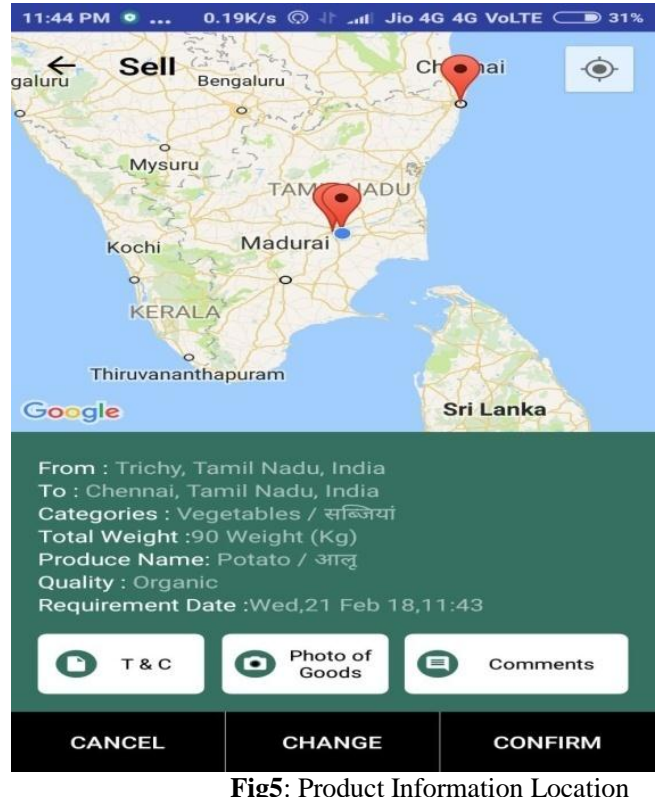

The bidding will be closed after some time based on item and day, the options will be closed after time period ends and the current buyer and seller will get notified through SMS. The item will be deleted from DB later. Bidding is different for different type of crop products, for vegetables bidding allowed only one day due to their lifetime, for products like rice or wheat bidding allowed for 3-4 days because that can be easily stored in store room.

\section{Decision Support System:}

Farmers can also get advices from experts for their queries like to identify disease and corresponding pesticides, to know best alternative crops and planting tips. Experts can also provide predicted information like rain fall prediction, weather prediction, estimated quantity and profit for their products that will help them to choose profitable crops. Fig- 4 shows an uploaded image of the crop by farmer to identify disease and best available pesticides by experts.

\section{Conclusions and Future Work}

Through e-application farmers and end-users both can be benefited by absence of middle man. It further helps to take decisions effectively by querying the problems to experts. By adding online advance payment can increase the transparent of e-auction. The grade allocation to the quality of the products in online can be useful to classify the products with more accuracy.

\section{References}

[1]. Shakeel-Ul-Rehman, M. Selvaraj and M. Syed Ibrahim "Indian Agricultural Marketing- A Review", Asian Journal of Agriculture and Rural Development, 2012 Vol. 2, No.1, pp.no. 69-75

[2]. N. Alexandratos, J. Bruinsma, et al., World agriculture towards 2030/2050: the 2012 revision, ESA Work Pap, vol. 3, 2012.

[3]. Xiaolan Fu and Shaheen Akter, 'Impact of Mobile Telephone on the Quality and Speed of Agricultural Extension Services Delivery: Evidence from the Rural e-services Project in India' International Conference on Agriculture Economist, 2012, issue no 2, pp.no. 132

[4]. Brithal, P. S., Jha, A. K. and Singh, H. (), "Linking Farmers to Market for High Value Agricultural Commodities", Agricultural Economics Research Review, 2007, Vol. 20, pp.no. 425-439.

[5]. C. Ascough, R. Maier, K. Ravalico and W. Strudley, "Future research challenges for incorporation of uncertainty in environmental and ecological decision-making", Ecological modelling, vol. 219, no. 3, pp.383-399, 2008. 